\title{
Cytotoxicity, Biocompatibility, and Biomineralization (1) of the New High-plasticity MTA Material
}

\author{
Luciano Tavares Angelo Cintra, PbD, ${ }^{*}$ Francine Benetti, MSc, * \\ Índia Olinta de Azevedo Queiroz, MSc, * Juliana Maria de Araújo Lopes, DDS, * \\ Sandra Helena Penba de Oliveira, PbD, ${ }^{\dagger}$ Gustavo Sivieri Araújo, PbD, * \\ and João Eduardo Gomes-Filbo, PbD*
}

\section{Ahstract}

Introduction: Mineral trioxide aggregate (MTA) has excellent biological properties, but its handling properties have been criticized for both ProRoot MTA (Tulsa Dental Products, Tulsa, OK) and white MTA-Angelus (MTA-Ang; Angelus Indústria de Produtos Odontológicos S/A, Londrina, PR, Brazil). Angelus MTA HP (high plasticity) (Angelus Indústria de Produtos Odontológicos $S / A$ ) has been introduced recently. Considering the importance of biological properties of materials that will be in contact with the tissues, this study evaluated the cytotoxicity, biocompatibility, and biomineralization of MTA HP compared with white MTA-Ang. Methods: L929 fibroblast cell lines were cultured, and cell viability was assessed at 6, 24, 48, and 72 hours using the alamar Blue assay (Thermo Fisher Scientific, Waltham, MA). A subcutaneous implant test was performed with polyethylene tubes containing 1 of the materials or empty tubes (control) using 20 Wistar rats. After 7 and 30 days of implantation, the tubes with surrounding tissues were removed for analysis using hematoxylin-eosin or von Kossa stain or they remained unstained for observation under polarized light. The results were statistically analyzed $(P<.05)$. Results: A significant increase in cell viability for MTA HP was observed after 24, 48, and 72 hours compared with the control $(P<.05)$. At 72 hours, MTA HP exhibited a higher viability compared with white MTA-Ang $(P<.05)$. Histologic analysis performed at 7 days showed moderate inflammation and a thick fibrous capsule in all groups $(P>.05)$. At 30 days, mild inflammation and a thin fibrous capsule were observed in all groups $(P>.05)$. All materials had structures positive for von Kossa and birefringent to polarized light. Conclusions: MTA HP showed biocompatibility and biomineralization similar to MTA-Ang. In addition, MTA HP showed increased fibroblast cell viability compared with white MTA-Ang after a longer period. (J Endod 2017;43:774-778)

\section{Key Words}

Biocompatibility, biomineralization ability, cytotoxicity, mineral trioxide aggregate

B iocompatible matethe formation of mineralized tissue are of great importance in clinical applications such as pulp exposure, root perforations, root-end fillings, and apex-

ification (1). Materials based on mineral trioxide aggregate (MTA) are materials with a composition largely based on Portland cement components (mainly di-and tricalcium silicate) and additional radiopacifying agents, such as bismuth oxide (2). The proportions of these components vary by brand. The great interest in this material is because of its lower cytotoxicity compared with other root-end filling materials $(3,4)$ and its ability to induce mineralized tissue formation $(2,5)$.

MTA became commercially available as ProRoot MTA (Tulsa Dental Products, Tulsa, OK). Later, gray and white MTA-Angelus (MTA-Ang) (Angelus Indústria de Produtos Odontológicos S/A, Londrina, PR, Brazil) were introduced (6). Despite the favorable properties of MTA-type products that support their clinical use, these first few products had drawbacks, such as a prolonged setting time, poor handling, and potential of discoloration $(2,7)$.

Recently, a new MTA-based material was placed on the market, MTA HP (Angelus Indústria de Produtos Odontológicos S/A). One of the differences of this new material over the old formulation of white MTA-Ang was the replacement of the distilled water by a liquid containing water and an organic plasticizer (8); the composition of this is not disclosed by the manufacturer. This liquid provides a higher plasticity, improving handling and inserting the material to the repair site. Furthermore, the replacement of the bismuth oxide radiopacifier by a calcium tungstate radiopacifier will avoid dental discoloration (8).

A recent study showed that MTA HP showed better push-out bond strength than its predecessor white MTA-Ang (9). The authors believe that the presence of calcium tungstate as a radiopacific agent in MTA HP contributed to the higher calcium release in the initial periods (10), promoting greater biomineralization and helping in the resistance of this material (11). Furthermore, the greater plasticity could improve the marginal adaptation, which would also contribute to this result (11). However, studies are

From the Departments of *Endodontics and †Basic Science, São Paulo State University (Unesp), School of Dentistry, Araçatuba, São Paulo, Brazil.

Address requests for reprints to Prof Luciano Tavares Angelo Cintra, Department of Endodontics, São Paulo State University (Unesp), School of Dentistry, R: José Bonifácio, 1193 Vila Mendonça, Araçatuba, São Paulo, Brazil. E-mail address: lucianocintra@foa.unesp.br

0099-2399/\$ - see front matter

Copyright (c) 2017 American Association of Endodontists.

http://dx.doi.org/10.1016/j.joen.2016.12.018 
needed to evaluate the cytotoxicity and biocompatibility of this material and its ability to induce the formation of hard tissue.

This study evaluated MTA HP, analyzing its in vitro cell viability, in vivo reaction in the subcutaneous tissue of rats, and its ability to induce mineralization assessed by von Kossa staining and structures birefringent to polarized light. White MTA-Ang was used for comparison.

\section{In Vitro Study}

\section{Materials and Methods}

Bell Bulture. Following a previous study (12), L929 mouse fibroblasts were grown in Dulbecco modified Eagle medium (GIBCO BRL, Gaithersburg, MD) supplemented with $10 \%$ fetal bovine serum (GIBCO BRL), streptomycin $(50 \mathrm{~g} / \mathrm{mL})$, and a $1 \%$ antibiotic/antimycotic cocktail (300 U/mL, $300 \mu \mathrm{g} / \mathrm{mL}$ streptomycin, and $5 \mu \mathrm{g} / \mathrm{mL}$ amphotericin $\mathrm{B})$ (GIBCO BRL) under standard cell culture conditions $\left(37^{\circ} \mathrm{C}, 100 \% \mathrm{hu}-\right.$ midity, $95 \%$ air, and $5 \% \mathrm{CO}_{2}$ ).

Sample Preparation. White MTA-Ang and MTA HP were mixed according to the manufacturer's instructions. MTA discs were prepared under aseptic conditions as previously described by Yoshino et al (13) with some modifications. Briefly, the discs were molded in a sterile cylindrical polyethylene tube (diameter $=5 \mathrm{~mm}$ and height $=3 \mathrm{~mm}$ ). The MTA discs were kept in a $5 \% \mathrm{CO}_{2}$ incubator at $37^{\circ} \mathrm{C}$ for 6 hours after mixing to set. After 6 hours, the discs were removed from the molds and sterilized by ultraviolet light for 1 hour in a biological cabinet (Bio Class I; Contained Air Solutions Ltd, Manchester, England). Each disc was immersed into $1 \mathrm{~mL}$ Dulbecco modified Eagle medium/10\% fetal bovine serum and incubated in a humidified atmosphere containing 5\% $\mathrm{CO}_{2}$ for 3 days. After 3 days, the discs were discarded, and the supernatants (eluate extract) were collected and filtered through a sterile $0.22-\mu \mathrm{m}$ filter (Sigma-Aldrich, St Louis, MO). The supernatant collected was referred to as white MTA-Ang extract or MTA HP extract. The extracts were diluted with culture medium (1:50) in this study.

Bell Viability Assay. Cell viability was determined using the alamar Blue reduction assay (alamar Blue Cell Viability Reagent; Thermo Fisher Scientific, Waltham, MA) following the manufacturer's instructions. Briefly, L929 fibroblasts were seeded into 24 -well plates $\left(10^{4}\right.$ cells/ $1 \mathrm{~mL}$ medium per well) and incubated for 24 hours in a humidified air atmosphere of $5 \% \mathrm{CO}_{2}$ at $37^{\circ} \mathrm{C}$ to allow attachment of the cells before adding MTA extracts. Both the MTA extract and the alamar Blue reagent were added to the cell medium. The control group received no extract. At 6, 24, 48, and 72 hours after the addition of MTA and alamar Blue, $200 \mu \mathrm{L}$ of the medium was transferred to a 96-well plate, and the optimal density was measured at wavelengths of 570 and $600 \mathrm{~nm}$. The reduction of alamar Blue was calculated with a formula provided by the manufacturer (1:10). The controls were cultured in a medium without MTA extracts. The experiments were performed in triplicate.

\section{In Vivo Study}

Subcutaneous Implant. Twenty male Wistar albino rats weighing approximately 250-280 $\mathrm{g}$ and 3 to 4 months of age were used in this study. The sample size for the animal experiment was established on the basis of previous studies involving analysis of materials in subcutaneous tissue of rats $(1,14,15)$. The study was approved and performed according to the guidelines of the ethical committee. Polyethylene tubes (Abbott Labs of Brazil, São Paulo, SP, Brazil) with a 1.0-mm internal diameter, 1.6-mm external diameter, and 10.0$\mathrm{mm}$ length were filled with white MTA-Ang or MTA HP prepared according to the manufacturer's recommendations; empty tubes were used as a control.

The surgical procedure was performed following previous studies $(14,15)$. The rats were anesthetized, their dorsa were shaved, and a 2.0-cm incision was made in a head-to-tail orientation with a \#15 Bard-Parker blade (BD, Franklin Lakes, NJ). The skin was reflected to create 2 pockets on the right side and 1 pocket on the left side of the incision. After the tubes were randomly implanted into the pockets, the skin was sutured. After 7 and 30 days, the rats were killed by an overdose of anesthetic solution. The implanted tubes, along with the surrounding tissues, were removed and fixed in $10 \%$ formalin solution at a $\mathrm{pH}$ of 7.0. The fixed specimens were processed and embedded in paraffin and serially sectioned into $5-\mu \mathrm{m}$ cuts for staining with hematoxylin-eosin and 10- $\mu \mathrm{m}$ cuts for staining according to the von Kossa technique; some slices were kept unstained for polarized light examination.

Histologic analysis was performed by a single calibrated operator in a blinded manner under light microscopy $(400 \times$, DM 4000 B; Leica, Wetzlar, Germany). The inflammation in the tissues close to the material was graded as follows: 1, no or few inflammatory cells and no reaction; 2 , less than 25 cells and little reaction; 3 , between 25 and 125 cells and moderate reaction; and 4, 125 or more cells and severe reaction (14). Fibrous capsules were considered to be thin when thickness was $<150 \mu \mathrm{m}$ and thick at $>150 \mu \mathrm{m}$ (14). Necrosis and calcification were recorded as present or absent (14).

Statistical Analysis. Data were submitted to statistical analysis using the GraphPad Prism (version 5.0; GraphPad Software Inc, La Jolla, CA) software program. Analyses of variance followed by Bonferroni

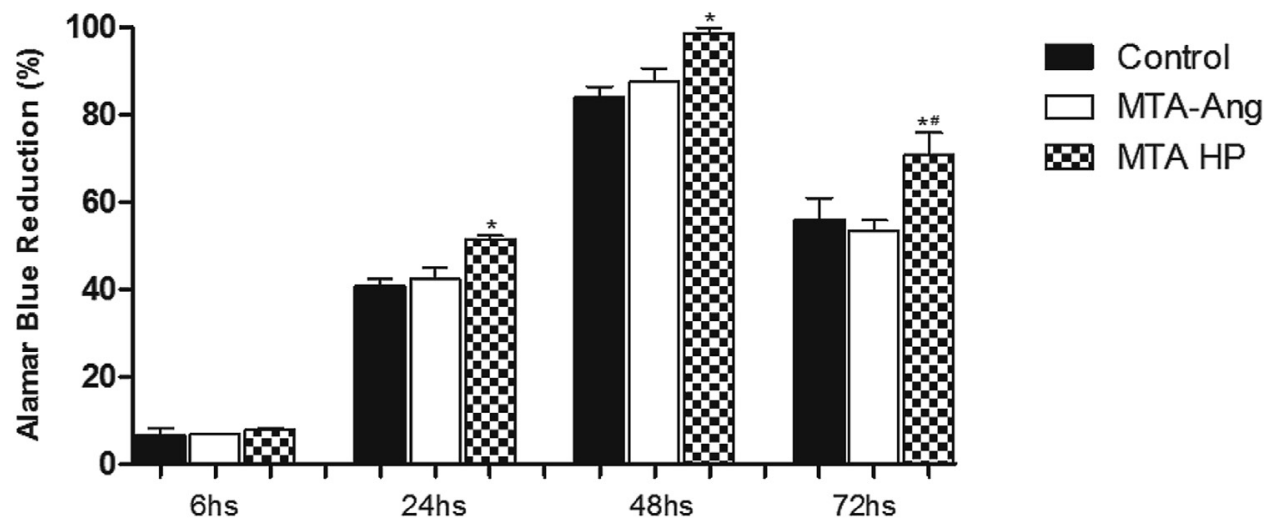

Figure 1. The effects of both MTA extracts on fibroblast viability after $6,24,48$, and 72 hours as determined by the alamar Blue reduction assay. The symbols indicate statistical differences between the groups within each time frame. $* P<.05$ vs control; $\# P<.05$ vs MTA-Ang. 

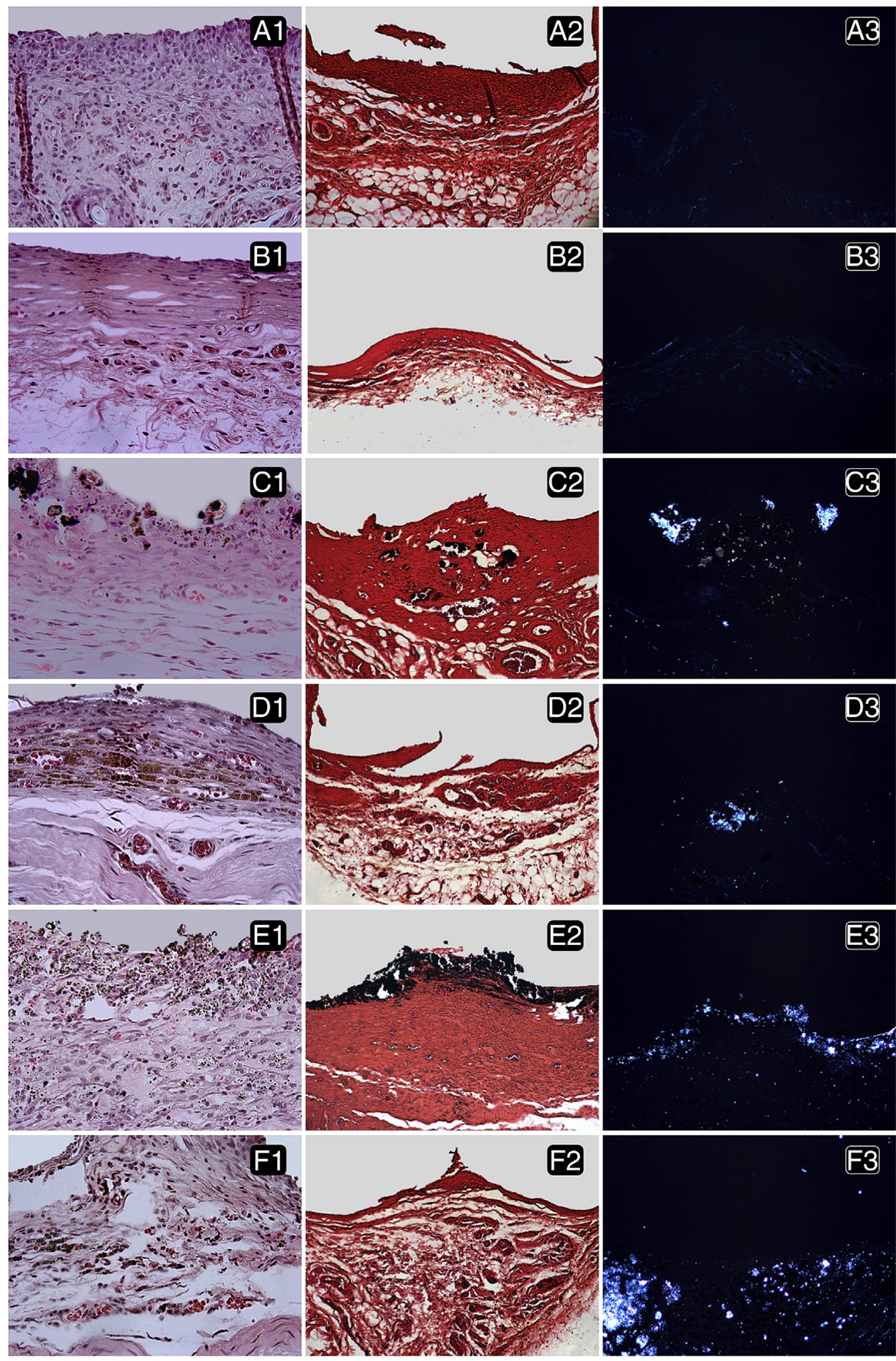

Figure 2. Representative images of the subcutaneous tissue reactions in the control and MTA groups. $(A$ and $B)$ Control group: $(A 1)$ presence of moderate inflammatory cell infiltration and thick fibrous capsule at 7 days, $(B 1)$ presence of mild inflammatory cell infiltration and thin fibrous capsule at 30 days, $(A 2$ and $B 2)$ absence of positive structures for von Kossa, and $(A 3$ and $B 3)$ absence of birefringent structures to polarized light. ( $C$ and $D)$ White MTA-Ang group: $(C 1)$ presence of superficial area of nuclear fragmentation, moderate inflammatory cell infiltration, and thick fibrous capsule at 7 days; (D1) mild inflammatory infiltrate and thin fibrous capsule in the tube opening at 30 davs; $(C 2$ and $D 2)$ presence of positive structures for von Kossa; and (C3 and $D 3)$ birefringent structures to polarized light. ( $E$ and $F)$ MTA HP group: $(E 1)$ areas of nuclear fragmentation with presence of moderate inflammatory infiltrate and thick fibrous capsule at 7 days, $(F 1)$ presence of mild inflammatory infiltrate and thin fibrous capsule in the tube opening at 30 days, $(E 2$ and $F 2)$ presence of positive structures for von Kossa; and (E3 and F3) birefringent structures to polarized light. (1) Hematoxylin-eosin staining, $400 \times$; (2) staining according to the von Kossa technique, 100×; (3) polarized light visualization, $100 \times$. 
correction were performed for parametric data and the Kruskal-Wallis test followed by the Dunn test for nonparametric data; $P<.05$ was considered significant.

\section{Cell Viability}

\section{Results}

Determination of the effects of both MTA extracts on fibroblast viability was performed using the alamar Blue reduction assay at 6 , 24, 48, and 72 hours (Fig. 1). Indeed, the higher reduction percentage level reflects great cell viability. The increase in cell viability was detected according to the time frame, with a significant decline at 72 hours for all groups evaluated $(P<.05)$. The results revealed a significant increase in cell viability for MTA HP extract after 24,48 , and 72 hours of cell exposure when compared with the control group $(P<.05)$. In addition, the MTA HP extract exhibited a higher viability compared with white MTA-Ang extract at 72 hours $(P<.05)$.

\section{Histologic Analysis}

Representative images of the groups can be observed in Figure $2 A-F$. At 7 days, in both MTA groups, a superficial layer of necrosis and nuclear fragmentation in close contact with the material were observed, which were not observed in the control group. Most specimens in all the groups showed moderate inflammation at 7 days; at this time, the fibrous capsule in the tube opening region was thick. At 30 days, the area of necrosis was no longer present, and a similar response between the groups was observed in that most specimens showed mild inflammation $(P>.05)$. From that point on, the fibrous capsule of all groups was thin (Table 1).

Structures positive for von Kossa staining and birefringent to polarized light were observed near the tube opening in both MTA groups at 7 and 30 days; these structures were not observed in the control group. The results of the histologic analysis are provided in Table 1.

\section{Discussion}

The American Association of Endodontists recommends that the use of a new material should be based on biological and clinical studies (16). Endodontic materials must have their biological properties screened by in vitro tests before their clinical use to minimize adverse effects. Moreover, materials that will be in permanent contact with the periapical tissues or the pulp tissue should exhibit low cytotoxicity and high biocompatibility (17), and the ability to induce a mineralized barrier is important for protecting the tissues (18). This study evaluated the cytotoxicity, biocompatibility, and mineralization capacity of MTA HP, comparing it with its precursor. The cytotoxicity assay showed higher cell viability and biocompatibility and biomineralization similar to white MTA-Ang

Available MTA-based materials on the market exhibit satisfactory histologic results $(14,15,19-21)$ and are widely used by clinicians
$(22,23)$; however, the disadvantages of the earliest MTA-type products have led to new formulations that combine good handling and mechanical and biological properties $(2,7)$. A long setting time and the difficulty in manipulation have been common disadvantages, especially for inserting the material into root-end fillings (5).

According to the manufacturer, MTA HP has a high plasticity compared with white MTA-Ang (8). The powder of the new formula is composed of tricalcium silicate, dicalcium silicate, tricalcium aluminate, calcium oxide, and calcium tungstate, whose particle size after hydration allows easy manipulation and insertion into the dental cavity: after handling, the consistency obtained is similar to a modeling mass, not sandy (8). In the present study, a difference in its consistency can be confirmed. The MTA HP powder is packaged in capsules, and the manufacturer's recommendation is to spatulate the contents of the capsule with 2 drops of the liquid for 40 seconds (8).

Indications for the use of MTA HP material are the same as its precursor including treatment of root perforations and furcation, sealing root resorption, root-end fillings, pulp capping, pulpotomy, apexification, and apical plugs (8).

This in vitro study confirmed that white MTA-Ang extract was similar to the control group and did not inhibit cell viability, which is consistent with previous investigations $(17,24,25)$. However, the ability of MTA-based cements to induce proliferation in cell culture has been shown to be significant when compared with the control (26). MTA HP showed a better response when compared with the control at 24, 48, and 72 hours and better than white MTA-Ang at 72 hours. These findings might be justified by the absence of bismuth oxide in the composition of MTA HP; studies showed a possible cytotoxic effect of bismuth oxide on the human osteoblastlike cells while in association with dicalcium silicate cement compared with this without the radiopacifier (27); bismuth oxide also increases the cytotoxicity in human dental pulp cell when added to Portland cement (28). Portland cement containing calcium tungstate showed an alkaline $\mathrm{pH}$, the release of calcium ions similar to Portland cement only (10), and good cell viability in periodontal ligament cells (29).

The addition of calcium tungstate to Portland cement may increase the infiltration of fluids (11). According to the authors, it is likely that calcium tungstate changes the structure of cement, forming cracks that increase infiltration; moreover, the physicochemical properties of this cement may favor these results. This factor might be compensated for in MTA HP because of its higher plasticity, which improves the marginal adaptation of the cement to the root walls and promotes greater bonding strength (9). Furthermore, it was observed that calcium tungstate contributes to a higher release of calcium ions, promoting greater biomineralization (30).

In the histologic analysis, we observed a superficial layer of necrosis at 7 days. Superficial necrosis is commonly observed when using MTA because of the alkalinity on adjacent tissues $(31,32)$. The material is considered biocompatible if the inflammatory reaction

TABLE 1. Inflammatory Score, Thickness of Fibrous Capsule, Biomineralization Ability, and Necrosis of All Groups

\begin{tabular}{|c|c|c|c|c|c|c|c|c|c|c|}
\hline \multirow[b]{2}{*}{ Time/P value } & \multirow[b]{2}{*}{ Groups* } & \multicolumn{4}{|c|}{ Scores } & \multirow[b]{2}{*}{ Median } & \multirow[b]{2}{*}{ Capsule } & \multirow{2}{*}{$\begin{array}{c}\text { Biomineralization } \\
\text { ability }(\%)\end{array}$} & \multirow[b]{2}{*}{ Necrosis (\%) } & \multirow[b]{2}{*}{$n$} \\
\hline & & 1 & 2 & 3 & 4 & & & & & \\
\hline 7 days & Control $^{a}$ & 0 & 2 & 5 & 3 & 3 & Thick & 0 & 0 & 10 \\
\hline \multirow{2}{*}{$P=.544$} & White MTA-Ang ${ }^{a}$ & 0 & 0 & 6 & 4 & 3 & Thick & 100 & 100 & \\
\hline & MTA HP & 0 & 0 & 6 & 4 & 3 & Thick & 100 & 100 & \\
\hline 30 days & Control $^{\mathrm{a}}$ & 2 & 6 & 2 & 0 & 2 & Thin & 0 & 0 & 10 \\
\hline \multirow[t]{2}{*}{$P=.572$} & White MTA-Ang ${ }^{a}$ & 1 & 5 & 4 & 0 & 2 & Thin & 100 & 0 & \\
\hline & MTA HPa & 1 & 6 & 3 & 0 & 2 & Thin & 100 & 0 & \\
\hline
\end{tabular}

*Same letters indicate no statistical difference among the groups $(P>.05)$. 
reduces to nonsignificant levels over time (33). In this study, the groups showed a moderate initial inflammatory response, which later became mild; yet, the inflammation by the materials did not differ statistically from the control group, corroborating previous studies that showed the biological properties of ProRoot MTA $(14,19,20)$ and gray and white MTA-Ang $(15,19,21)$. This study showed that MTA HP could be considered to have a biocompatibility similar to white MTA-Ang.

Calcium hydroxide formed during the setting of MTA-type products will react with carbon dioxide in the tissues to form calcite crystals, which are birefringent to polarized light and serve as a nucleus for calcification (34). These calcifications can be observed by von Kossa staining. The biomineralization ability of white MTA-Ang and MTA HP was detected by the presence of structures birefringent to polarized light and von Kossa-positive staining.

This study helps to illuminate the properties of MTA HP. However, this is the first study that has evaluated its biological properties. More research is necessary to comprehend the biological effects of this new material, such as the analysis of fresh sealer, because studies point to significant differences in toxicity when comparing set and fresh endodontic sealers (35).

\section{Conclusion}

MTA HP showed biocompatibility and biomineralization similar to white MTA-Ang. In addition, MTA HP promoted an increase in the fibroblast cell viability compared with white MTA-Ang after a longer period.

\section{Acknowledgments}

Supported by CNPq (305969/2015-3).

The authors deny any conflicts of interest related to this study.

\section{References}

1. Mori GG, Teixeira LM, de Oliveira DL, et al. Biocompatibility evaluation of biodentine in subcutaneous tissue of rats. J Endod 2014;40:1485-8.

2. Parirokh M, Torabinejad M. Mineral trioxide aggregate: a comprehensive literature review_part I: chemical, physical, and antibacterial properties. J Endod 2010;36: $16-27$

3. Torabinejad M, Hong CU, Pitt Ford TR, Kettering JD. Cytotoxicity of four root end filling materials. J Endod 1995;21:489-92.

4. Keiser K, Johnson CC, Tipton DA. Cytotoxicity of mineral trioxide aggregate using human periodontal ligament fibroblasts. J Endod 2000;26:288-91.

5. Parirokh M, Torabinejad M. Mineral trioxide aggregate: a comprehensive literature review-part III: clinical applications, drawbacks, and mechanism of action. J Endod 2010:36:400-13.

6. Camilleri J. The chemical composition of mineral trioxide aggregate. J Conserv Dent 2008;11:141-3.

7. Wongkornchaowalit N, Lertchirakarn V. Setting time and flowability of accelerated Portland cement mixed with polycarboxylate superplasticizer. J Endod 2011;37: 387-9.

8. Angelus MTA Repair HP. Produtos Angelus. Available at: http://angelus.ind.br/MTAREPAIR-HP-292.html. Accessed September 4, 2016.

9. Silva EJ, Carvalho NK, Zanon M, et al. Push-out bond strength of MTA HP, a new high-plasticity calcium silicate-based cement. Braz Oral Res 2016:30:e84.

10. Hungaro Duarte MA, Minotti PG, Rodrigues CT, et al. Effect of different radiopacifying agents on the physicochemical properties of white Portland cement and white mineral trioxide aggregate. J Endod 2012;38:394-7.

11. Amoroso-Silva PA, Marciano MA, Guimarães BM, et al. Apical adaptation, sealing ability and push-out bond strength of five root-end filling materials. Braz Oral Res 2014;28:1-6.
12. Gomes-Filho JE, Watanabe S, Gomes AC, et al. Evaluation of the effects of endodontic materials on fibroblast viability and cytokine production. J Endod 2009;35:1577-9.

13. Yoshino P, Nishiyama CK, Modena KC, et al. In vitro cytotoxicity of white MTA, MTA Fillapex and Portland cement on human periodontal ligament fibroblasts. Braz Dent J 2013;24:111-6.

14. Cintra LT, Ribeiro TA, Gomes-Filho JE, et al. Biocompatibility and biomineralization assessment of a new root canal sealer and root-end filling material. Dent Traumatol 2013;29:145-50.

15. Gomes-Filho JE, de Azevedo Queiroz ÍO, Watanabe S, et al. Influence of diabetes mellitus on tissue response to MTA and its ability to stimulate mineralization. Dent Traumatol 2015;31:67-72.

16. American Association of Endodontists. New Materials/Technologies Position Paper. Chicago: American Association of Endodontists; 2013.

17. Willershausen I, Wolf T, Kasaj A, et al. Influence of a bioceramic root end material and mineral trioxide aggregates on fibroblasts and osteoblasts. Arch Oral Biol 2013; 58:1232-7.

18. Leonardo MR, Bezerra da Silva LA, Filho MT, Santana da Silva R. Release of formaldehyde by 4 endodontic sealers. Oral Surg Oral Med Oral Pathol Oral Radiol Endod 1999;88:221-5.

19. Cintra LT, de Moraes IG, Estrada BP, et al. Evaluation of the tissue response to MTA and MBPC: microscopic analysis of implants in alveolar bone of rats. J Endod 2006; 32:556-9.

20. Cintra LT, Bernabé PF, de Moraes IG, et al. Evaluation of subcutaneous and alveolar implantation surgical sites in the study of the biological properties of root-end filling endodontic materials. J Appl Oral Sci 2010;18:75-82.

21. Gomes-Filho JE, de Moraes Costa MM, Cintra LT, et al. Evaluation of rat alveolar bone response to Angelus MTA or experimental light-cured mineral trioxide aggregate using fluorochromes. J Endod 2011;37:250-4.

22. Azim AA, Lloyd A, Huang GT. Management of longstanding furcation perforation using a novel approach. J Endod 2014;40:1255-9.

23. Agrawal PK, Wankhade J, Warhadpande M. A rare case of type III dens invaginatus in a mandibular second premolar and its nonsurgical endodontic management by using cone-beam computed tomography: a case report. J Endod 2016:42:669-72.

24. Camargo SE, Camargo CH, Hiller KA, et al. Cytotoxicity and genotoxicity of pulp capping materials in two cell lines. Int Endod J 2009;42:227-37.

25. Bin CV, Valera MC, Camargo SE, et al. Cytotoxicity and genotoxicity of root canal sealers based on mineral trioxide aggregate. J Endod 2012:38:495-500.

26. Cornélio AL, Rodrigues EM, Salles LP, et al. Bioactivity of MTA Plus, Biodentine and experimental calcium silicate-based cements in human osteoblast-like cells. Int Endod J 2017;50:39-47.

27. Chiang TY, Ding SJ. Comparative physicochemical and biocompatible properties of radiopaque dicalcium silicate cement and mineral trioxide aggregate. J Endod 2010; 36:1683-7.

28. Min KS, Chang HS, Bae JM, et al. The induction of heme oxygenase-1 modulates bismuth oxide-induced cytotoxicity in human dental pulp cells. J Endod 2007;33: 1342-6.

29. Gomes-Cornelio AL, Salles LP, Campos da Paz M, et al. Cytotoxicity of Portland cement with different radiopacifying agents: a cell death study. J Endod 2011;37: 203-10.

30. Huffman BP, Mai S, Pinna L, et al. Dislocation resistance of ProRoot Endo Sealer, a calcium silicate-based root canals sealer, from radicular dentine. Int Endod J 2009; 42:34-46.

31. Tronstad L, Andreasen JO, Hasselgren G, et al. pH changes in dental tissues after root canal filling with calcium hydroxide. J Endod 1981:7:17-21.

32. Gomes-Filho JE, Watanabe S, Lodi CS, et al. Rat tissue reaction to MTA FILLAPEX®. Dent Traumatol 2012;28:452-6.

33. Silveira CM, Pinto SC, Zedebski Rde A, et al. Biocompatibility of four root canal sealers: a histopathological evaluation in rat subcutaneous connective tissue. Braz Dent J 2011;22:21-7.

34. Gomes-Filho JE, de Moraes Costa MT, Cintra LT, et al. Evaluation of alveolar socket response to Angelus MTA and experimental light-cure MTA. Oral Surg Oral Med Oral Pathol Oral Radiol Endod 2010;110:e93-7.

35. Camps J, About I. Cytotoxicity testing of endodontic sealers: a new method. J Endod 2003;29:583-6. 